\title{
Editorial Getting nowhere fast? Social work and its impact in the child, youth and family sector
}

Jennifer Lehmann and Rachael Sanders

I was recently challenged by a colleague to think about the sticky question of what social work, as a discipline, has achieved over the last 40-50 years. Being challenged about the efficacy of social work and the discipline's capacity for lasting impacts is hardly a new experience. Many social workers will have confronted the opinions of clients, managers, family members and the public about the contributions or otherwise that they perceive social workers to offer. I have had these experiences too, but there are particular times when such comments remain in one's memories. After the elapse of many years I do not claim to have total accuracy of recall, but perhaps the first time I was shaken by a challenge to my noble presumptions was when Dr John Paterson, Secretary of the Department of Health and Community Services, Victoria, spoke at a meeting of child protection workers around 1989-90. He declared that he thought a mature accountant could do as well in the role. As others have recalled, Dr Paterson 'did not blush to ignore traditional codes on the role of public servants in the policy process and overtly sought to participate in normative statements about policy' (Barraclough \& Smith, 1994 , p. 16). He was known for making offensive remarks. He described disability advocacy bodies as 'piss and wind' groups, denigrating them as people more interested in talk than getting their hands dirty delivering services (Milburn, 1993, p. 1). He precipitated great angst amongst public servants.

Years later, I was confronted again about social work's efficacy. This time it was by an academic (not a social worker) with whom I had an association through my $\mathrm{PhD}$ studies. The conversation was to inform me of Gabriele Bammer's work, in the course of which it was suggested to me that disciplines like social work were on the way out. There would be no place for a discipline that was siloed and failed to address much broader social, health and environmental issues in a cross-disciplinary fashion. In hindsight, this was not the most useful interpretation of Bammer's work (e.g., Bammer, 2005, 2017). In its current iteration on her website (https://researchers. anu.edu.au/researchers/bammer-g), Bammer's work is concerned with 'tackling complex problems' with 'improved theory and methods' needed for:

1. '[the] synthesis of a range of knowledge and perspectives (from relevant disciplines and stakeholders) to improve understanding of the problem,

2. more comprehensive understanding and management of unknowns, as action usually needs to occur in the face of incomplete knowledge,

3. using the improved understanding of the problem plus the improved grasp of unknowns to support decision makers and practitioners in government, business and civil society.'

Under her university staff profile, Bammer describes her research interest as being the development of a new discipline of 'Integration and Implementation Sciences' to 'improve research strengths for tackling complex real-world problems through synthesis of disciplinary and stakeholder knowledge, understanding and managing diverse unknowns and providing integrated research support for policy and practice change' (Bammer, 2017). Clearly, her work is closely focused on the issues of uncertainty and complexity, both of which are familiar to social workers around the globe. Moreover, she stresses the need to

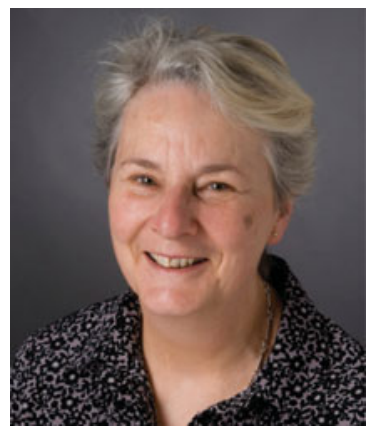


integrate knowledge from a wide range of disciplines something I had always believed social work did particularly skilfully.

It is confronting, though, to imagine your discipline disappearing, condemned as irrelevant to contemporary social issues and failing to meet expectations or create positive change. Turning to our professional bodies may provide some reassurance and endorsement for our roles in the child, youth and family sector. In Australia, a document on Child Protection, produced by the Australian Association of Social Workers (AASW), acknowledges that social workers practise in a range of roles 'including direct case work, management and policy'. The document also states:

No other professional discipline is so immersed in the areas of knowledge that are essential for quality relationshipbased child protection practice. As a result, social workers are recognised throughout the world as the core professional group in child protection policy, management and practice. Social workers offer a unique and valuable contribution in providing appropriate and targeted child-centred services as well as facilitating referral pathways that ensure the linking of services, access and equity (AASW, 2015, p. 6).

Not everyone agrees so wholeheartedly, and views on the efficacy of social work vary from country to country according to professional standards and policies observed. Gillingham (2016), for instance, wrote in response to Eileen Munro's report into child protection in England and Wales that, in Australia, social work 'is not the key profession in child protection' and that 'Australia stands alone in not requiring those who work at the frontline of child protection services to be qualified social workers' (p. 84). This is not to deny the positive impacts that countless clients have experienced as a result of social workers' endeavours to engage, understand and work with people facing disadvantage. However, social work has been criticised for not making a fundamental difference to the level of disadvantage people experience, regardless of whether social workers are involved in child protection services, or the broader child, youth and family sector.

Even a cursory look at the statistics related to child protection demonstrates that there has been no reduction in the number of reports or substantiations of child abuse in either Australia, the United Kingdom or the USA - all countries that, in global terms, could be considered wealthy and sufficiently resourced to be able to reduce disadvantage and implement population-based prevention measures. In fact, there are increases in the number and proportions of children and young people needing a child protection response in Australia and the United Kingdom, while the trend in the USA is stable (Australian Institute for Health and Welfare (AIHW), 2017; Bentley, O'Hagan, Raff, \& Bhatti, 2016; Child Trends, 2016; Child Welfare Information Gateway, n.d.; Department of Education, 2016). And, while this is only one way of measuring outcomes, it is likely there are ongoing concerns about the level of service delivery to these children and their families that relate to service access, timeliness and expertise. Many would also argue that there need to be population-based responses that address disadvantage across its variety of iterations, from income inequality and discrimination to drug use, family violence and parenting behaviours.

By contrast, the International Federation of Social Workers (IFSW) (2017) takes a broader perspective on what social work involves. Under its 'What we do' webpage the IFSW describes itself as 'a global organisation striving for social justice, human rights and social development through the promotion of social work, best practice models and the facilitation of international cooperation.' It goes on to state that the Federation

supports its 116 country members by providing a global voice for the profession. IFSW has been granted Special Consultative Status by the Economic and Social Council (ECOSOC) of the United Nations and the United Nations Children's Fund (UNICEF). In addition, IFSW is working with the World Health Organization (WHO), the Office of the United Nations High Commissioner for Refugees (UNHCR), the Office of the United Nations High Commissioner for Human Rights (OHCHR).

Nonetheless, the promotion of social work by the IFSW appears to be more effective in some member countries than others. Truell (2017), writing for The Guardian about World Social Work Day, provides a marker of hope that social workers in some countries are not only recognising the day but also taking social action together with clients. He comments that the British Association of Social Workers held a Boot Out Austerity march that took place between 19 and 26 April this year. During that period 'social workers, service users, carers and others [walked] almost 100 miles, visiting food banks and social care settings under threat from funding cuts along the route, to hear from those whose lives have been devastated by austerity' (para.1) in Britain. He further states that there were marches held in other countries, including European and African nations. This contributes, Truell claims, to not only social reform, but demonstrates that working alongside clients, carers and others contributes to empowerment and the breaking down of social isolation and dependence. However, while World Social Work Day 2017 was reported in the United Kingdom (Truell, 2017), it made no headlines in any Australian newspapers that I could locate and had limited coverage in other nations, being predominantly an event highlighted by social work agencies and websites.

So, if it is the case that social work has difficulties promoting social change, who is advocating at a policy level for change that might result in more fundamental shifts and the reduction of disadvantage and need? Organisations like 
the Australian Council for Social Services (ACOSS, n.d.) certainly focus strongly on policy issues, but social workers are not featured as staff. Other advocacy groups take up specific issues such as the handling of refugees, international children's issues and wellbeing. For instance, the International Society for the Prevention of Child Abuse and Neglect (ISPCAN, 2017) asserts that it is 'the only multidisciplinary international organization that brings together a worldwide cross-section of committed professionals to work toward the prevention and treatment of child abuse, neglect and exploitation globally'. Within that 'cross-section', however, only 2 of the 20 international members of the Executive Committee and Council have a Master of Social Work qualification, while the majority are medically qualified (ISPCAN, 2017).

It seems that those major organisations working towards social justice at policy levels are putting into practice the multidisciplinary approaches called for by Bammer more visibly than the representative bodies of social work itself. At the same time, social media now provides opportunities for people of all walks of life to participate in movements for change, with key groups, such as GetUp!, providing powerful platforms for advocacy. For social workers, the inability to speak out, due to the confidentiality clauses and privacy policies of their employing organisation, has at least been partially alleviated through the anonymity of petition sites and the determination of other voices to be heard. But I wonder if many social workers are actively using social media to further social change?

The regard given by organisations to the values of social work is another factor to be considered. Truell and Jones (2014), in discussing The Agenda for social work developed between the IFSW, the International Association of Schools of Social Work and the International Council on Social Welfare and International, observed the need for a set of commitments to:

the internal activities of our own organizations, directed towards ensuring that policies and standards are consistent with addressing the root causes of poverty and oppression and promoting sustainable social environments which make a reality of respect for human rights and dignity. (pp. 8-9)

Recognition was also given to 'the significance of education and training and of the working environment for effective and ethical social work practice [including] commitments to coordinate research and activity to improve these elements'.

With the shift to contracting out, the privatisation of services, and constant restrictions on government funding across many areas of welfare endeavour, there has been little opportunity to make fundamental changes to social systemic factors. Most non-government organisations (NGOs) are focussed on achieving the client-related targets set by funding bodies, and have adopted business models that make them, at best, quasi profit-making entities, competing for funding from anywhere it might come. Darwin is a prime example of a city where the competition between NGOs has resulted in an array of agencies 'setting up shop' there to secure funding or promulgate a multistate brand. Nor are NGO staff are contracted to provide programs that essentially challenge the status quo. One social worker, who shall remain anonymous, was recently heard to state publically that the work to be done on contract should only be that specified in the contract! Now that is a very limiting perspective indeed for any representative of a discipline that claims to have an overarching commitment to improving the situation of disadvantaged individuals and groups.

Funding and contract-related pressures in the child and family sector have also served to lower the level of qualifications required of staff, thus diminishing the depth of disciplinary expertise required of staff delivering child welfare services. This results in lower wages, certainly in the non-government and charitable sectors, which allows these organisations to remain barely viable in the constrained funding environment we currently experience. A broadening of disciplinary expertise has also been noted in Australia, with a variety of qualifications considered acceptable ranging from Certificate courses obtained through TAFEs to undergraduate education, teaching, sociology and psychology degrees. This contrasts with public and health authorities that require solid professional qualifications and offer higher salaries.

One of the issues that sits alongside the broadening of training deemed acceptable for child welfare roles is whether or not the skills and knowledge are as efficacious as those used by social workers. Challenges to social work as the most efficacious discipline in the child welfare sector compound these factors, and a few studies have been done to test the benefits and outcomes of differing disciplinary approaches. In the United States, Rubin and Parrish (2012) reviewed the literature and a number of studies related to social work's efficacy as a discipline relevant to child welfare, concluding 'The lack of compelling evidence favouring social workers in public child welfare agencies might be particularly disappointing' (p. 318). Clearly, it is not a given that social work is the principal discipline desired for child welfare roles and further research would be useful. Other disciplines, such as paediatrics and neurology (which have led to improved understandings of trauma), have already made strong contributions to specialist areas of child welfare, and a stronger understanding of what social work can offer would assist the efforts within the social work disciplinary bodies, internationally, to promote the profession. However, there is as yet little evidence of increasing efforts to promote the discipline at all in the face of 'constrained economic circumstances', which have the effect of legitimating outcomes obtained through the employment of non-social work staff. Nor, at the moment, are there studies on the horizon that might serve to reaffirm the values and status of social work more broadly. 
As difficult as the last 20 years have been for social work with the managerialist agenda, fiscal constraint and a heightening of regulatory and accountability processes, there is the argument that social workers are able to achieve change from within organisations so long as they continue to be employed and are committed to working towards systemic and programmatic change. In Australia, there has certainly been evidence of this in the past. In the 1970s, social workers, such as David Green in Victoria, were influential from within in moving state government welfare services from a centralised model to a regionalised one. Connie Benn was also influential from outside government. She was employed by the Brotherhood of St Laurence, where from 1972 to 1975 she headed the new Family Centre. As the AASW (2017) records, 'The Centre was established to try to identify ways of breaking the cycle of inter-generational poverty, and developed a new theory of social work called the Developmental Approach, which she believed would create more sustainable change than individual casework'. The Connie Benn Centre, developed in her memory, describes her as 'one of the most significant social innovators and policy reformers in Victoria. Her work in Fitzroy changed the community development and welfare models of social work across the country' (Yarra City Council, 2017). Others promoted the closure of children's institutions - the deinstitutionalisation movement of the 1980s (Swain, 2014) - in favour of family group homes and foster care for the greater benefit of children in need of out-of-home care. Social workers continue to argue for individualised services for clients and for funding to meet client needs, and many are highly skilled at working within bureaucratic regimes to achieve their ends.

Yet, there is little evidence that the social work disciplinary 'voice' is currently being heard and effective when there is demand for more basic systemic change in relation to child welfare. It is noticeable when someone like Rosie Batty, who lost her son due to family violence, leads the way nationally in terms of demanding change from government in the form of different funding models and the development of appropriate services (Luke Batty Foundation, 2017). And, it is noticeable when there is demand for change in relation to the detention of refugees, and the management of young men and women in juvenile justice systems.

My own conclusion, albeit largely developed from an Australian perspective, is that social work, as a discipline, continues to struggle with influence, impact, and image, at least in part because it has been slow to expose and confront the anomalies of practising within the thrall of a capitalist agenda (Boetto, 2017). Perhaps our discipline has always been on the back foot, taking on language and processes such as 'diagnosis' to emulate the medical professions - and struggling, like other disciplines dominated by women, to achieve professional recognition and a place at the policy table. For now, it seems as though we have also forfeited the social action and language and processes of advocacy, once integral to our work, in a manner that echoes psychology. Hence, 'casework' remains the dominant paradigm. As the NGO agencies for which we work take on increasingly hardcore business models, social work has stayed mute, while old-fashioned vocabularies of charity have been put back into circulation by lazy marketing campaigns reliant on 'feel good' messages and stereotyping. In fact, philanthropy and fundraising for charities is now a career all of its own as indicated by the likes of OKP Philanthropy and Fundraising Consultants - Australia and New Zealand (see http://okp.com.au/) and Burnett Works (see http://burnettworks.co.uk/). We, the public, are told we must respond to the misery and victimisation of others - without demanding fundamentally different approaches to resolving critical issues of disadvantage. And where are the social workers doing community development? Has social media made us obsolete in this domain by emphasising entrepreneurship, the case specific, and favouring 'sexy' messages over a thoughtful, evolving commitment to localisation and the devolution of decision-making and democratic process? If, as many academic teaching staff believe, academic standards required for entrance to social work courses are declining, might this also be a factor in why radicalisation and demands for change have diminished?

Boetto (2017) comments that 'Social work operates in a global community where many of the world's poorest citizens bear the burden of environmental impacts associated with the damaging effects of privileged industrial societies.' (p. 57). She acknowledges the contradictions of social work operating within a capitalist framework that benefits the wealthy rather than improving the situation of the many and the disadvantaged; and she proposes a new model of social work - a Transformative Eco-social Model. Boetto's (2017) model is presented as three concentric inter-related circles. The innermost circle is the ontological or 'being' position taken by the social work professional, in relation to which Boetto describes the need for 'social workers to adopt a broader ontological base involving a conceptualisation of the 'self' as a relational part of a much larger system' (p. 53). The second circle is that of 'thinking' or the epistemological position taken by social work. This level involves consideration of 'the application of knowledge and professional values that inform our approach and make practice purposeful and assist with understanding and organising complex information' (p. 54). The outer circle addresses the practice, or 'doing' of social work and 'involves personal, individual, group, community and political dimensions of practice' (p. 58). Boetto (2017) argues that 'Acknowledging the inter-dependence between personal, individual, collective, community and political dimensions of eco-social practice provides the opportunity for social workers to identify a range of strategies conducive to transformative change within the profession and broader society' (p. 62).

This summary of Boetto's work fails to do justice to the fundamental challenges her model poses to existing 
systemic, consumer and related behaviours - behaviours that increase the disadvantage of those who are already vulnerable in our societies, and who will become more so in the face of climate and ecological disruption. Professionals currently practising, as busy as they are, would benefit from reading the Boetto article, which clearly challenges how we think, form our knowledge and value positions, and act in the real world with our clients, organisations, and political systems. Whether or not this thoughtful, provocative model can carry the discipline beyond current boundaries and barriers remains to be seen.

Jennifer Lehmann

This issue of Children Australia comprises two sections. The first contains the final three papers that stem from the Australian Childhood Foundation (ACF) 2016 International Childhood Trauma Conference. The second part includes papers that cover a broad range of topics from some of our regular contributors.

As pointed out by the guest editors of the June special issue, the conference discussions were 'focussed on the everyday realities of what it means to integrate the evidence from the neurobiology of attachment disruption and trauma into therapeutic approaches and practices' (Tucci \& Mitchell, 2017, p.1). The final four articles presented here extend the therapeutic and practice based discussions further. The first two papers are interesting practice commentaries. The first, by Oliva Powell and Kathy Morrison, examines the nature of family violence on children's wellbeing, experiences of trauma and some of the practice implications for providing therapeutic support to young people who are or have experienced family violence related trauma. The purpose of their article is to expand practitioner knowledge and skills to help improve diagnostic and treatment outcomes for children who are impacted by family violence.

In their paper entitled 'Relationship building, collaboration and flexible service delivery: The path to engagement of refugee families and communities in early childhood trauma recovery services', Signorelli, Gluckman, Hassan, Coello, and Momartin examined the reasons for refugee families' poor engagement with childhood services. The authors identified access, distrust of services, health and settlement issues, stigma, unfamiliarity with early childhood programmes, fear of child protection and other legal systems as barriers to early childhood programmes. The authors discuss a community engagement model that aims to address these issues and develop ways to better engage refugee groups with childhood services.

A literature review by Mary Jo McVeigh examines children and young people's voice, or lack thereof, in studies that evaluate therapeutic interventions aimed at children who have experienced maltreatment. The author acknowledge the valuable insight offered by young people and support the idea that young people should be provided greater participation and authority in evaluations to do with their care.

That concludes the articles derived from the ACF conference. We would like to thank Joe Tucci and Janise Mitchell for their continued support and contribution to the journal. The conferences run by the ACF make an important contribution to the field and we are pleased to be able to bring much of its content together for future reference.

Part two of this issue contains a number of interesting papers on a diverse range of topics.

It begins with an important study by Fernandez and colleagues who explored the experiences of care leavers who lived in various forms of institutional care between 1930 and 1989. While they found many participants displayed significant resilience, they also identified the numerous challenges and difficulties faced by these participants during and after their care experiences, many of which have had lasting impacts on their lives.

A paper by Frank Ainsworth examines the use of section 106A of the Children and Young Persons (Care and Protection) Act 1998 in the New South Wales Children's Court. Ainsworth undertook an analysis of the use of this section that was inserted into the Act by way of an amendment in November 2006. The amendment means that if a parent has had a child removed from their care then that information can be used as evidence for any subsequent children who are thought to be in need of care and protection and are subject to removal. Ainsworth found that if section 106A was cited in Court documents, then restoration was less likely to occur, but he did not find correlations between the use of this section and family characteristics or demographics.

Karen Struthers, Clare Tilbury, and Grace Williams have undertaken an evaluation of a youth peer-led programme called R4Respect. The programme promotes positive and respectful relationships amongst young people and their families as a way of preventing family violence. Interviews with peer educators and adult stakeholders indicate that the programme is successful in engaging young people as peer-educators and potentially plays a pivotal role in the prevention of domestic violence.

The final article, by Dominic McSherry and Montserrat Fargas Malet, is a thought provoking response to an article published in Children Australia entitled 'Family foster care: Can it survive the evidence?' by Frank Ainsworth and Patricia Hansen. The authors outline a number of concerns they have about the perspective taken towards outcomes in foster care and thought it important to put forward some alternate views within the context of current literature and knowledge. McSherry and colleagues would like to extend the exchange of ideas further and will be developing a special issue in 2018 that aims to present an international perspective on contemporary issues and dilemmas regarding outcomes for children in care.

This issue of Children Australia concludes with a book review by Frank Ainsworth. Frank highly recommends reading Blinded by Science. The social implications of epigenetics 
and neuroscience written by Wastell and White (2017) as it offers some thought provoking views on the way we engage with literature and scientific evidence.

Rachael Sanders

\section{References}

Australian Association of Social Workers (2015). AASW practice series - Scope of social work practice: Social work in child protection. Retrieved from https://www.aasw. asn.au/document/item/8331

Australian Association of Social Workers (2017). Concetta Benn (1926-2011). Retrieved from https://www.aasw. asn.au/victoria/spoken-memories/connie-benn

Australian Council for Social Services (n.d.). ACOSS staff. Retrieved from http://www.acoss.org.au/acoss-staff/

Australian Institute for Health and Welfare (2017). Child protection in Australia 2015-16. Child welfare series no. 66. Cat. no. CWS 60. Canberra: AIHW. Retrieved from http:// www.aihw.gov.au/publication-detail/?id=60129558626; http://www.aihw.gov.au/child-protection/

Bammer, G. (2005). Integration and implementation sciences: Building a new specialization. Ecology and Society, 10(2), 6 [online]. Retrieved from: http://www.ecologyandsociety. org/vol10/iss2/art6/

Bammer, G. (2017). Staff profile. Canberra: Australian National University. Retrieved from https://researchers.anu. edu.au/researchers/bammer-g

Barraclough, S., \& Smith, J. (1994). Change of government and health services policy in Victoria, 1992/93. Australian Health Review, 17(4), 7-21.

Bentley, H., O’Hagan, O., Raff, A., \& Bhatti, I. (2016). How safe are our children?: The most comprehensive overview of child protection in the UK. UK: National Society for the Prevention of Cruelty to Children.

Boetto, H. (2017). A transformative eco-social model: Challenging modernist assumptions in social work. British Journal of Social Work, 47(1), 48-67. doi: 10.1093/bjsw/bcw149.

Child Trends DataBank. (2016). Child maltreatment. Retrieved from https://www.childtrends.org/indicators/ child-maltreatment/

Child Welfare Information Gateway (n.d.). Child abuse and neglect statistics. Retrieved from https://www. childwelfare.gov/topics/systemwide/statistics/
Department for Education (2016). Characteristics of children in need: 2015 to 2016. SFR 52/2016. Retrieved from https:/www.gov.uk/government/uploads/system/uploads/ attachment_data/file/564620/SFR52-2016_Main_Text.pdf

Gillingham, P. (2016). Social work and child protection in Australia: Whose job is it anyway? Practice, 28(2), 83-96. doi: 10.1080/09503153.2015.1074670.

International Society for the Prevention of Child Abuse and Neglect (ISPCAN) (2017). Who we are. Retrieved from https://www.ispcan.org/who-we-are/

Luke Batty Foundation (2017). Luke Batty Foundation. Retrieved from https://lukebattyfoundation.org.au/aboutus/.

Milburn, C. (1993). All talk, no action riles welfare chief. The Age, 12 August, 1

Rubin, A., \& Parrish, D. (2012). Comparing social worker and non-social worker outcomes: A research review. Social Work, 57(4), 309-320. doi: 10.1093/sw/sws015.

Swain, S. (2014). History of institutions providing out-ofhome care to children. Sydney, Australia: Royal Commission into Institutional Responses to Child Sexual Abuse. Retrieved from https://www.childabuseroyalcommission. gov.au/getattachment/14b02387-425f-4a7b-9161-31b97 ce4dded/History-of-institutions-providing-out-of-homeresi

Truell, R. (2017). Why social workers are marching 100 miles in protest against austerity. The Guardian. Retrieved from https://www.theguardian.com/social-care-network/2017/ apr/13/social-workers-protest-march-againstgovernment-austerity

Truell, R., \& Jones, D. (2014). The global agenda for social work and social development: Extending the influence of social work. Retrieved from http://cdn.ifsw.org/ assets/ifsw_24848-10.pdf

Tucci, J., \& Mitchell, J. (2017). Editorial: Weaving trauma into the everyday - neuroscience, evidence and reflections from practice. Children Australia, 42(2), 73-74. doi:10.1017/cha.2017.21

Wastell, D., \& White, S. (2017). Blinded by science: The social implications of epigenetics and neuroscience. Bristol, UK: Policy Press.

Yarra City Council (2017). The Connie Benn Centre. Retrieved from: http://www.yarracity.vic.gov.au/services/ Family-and-Children-services/connie-benn-centre/ 